normal. On percussion the right side was nearly as resonant as the left. The liver could not be felt below the ribs. He stated that he had not coughed up any fluid and there were no signs of a pointing abscess anywhere.

The case appears to have been one of natural cure by absorption. The poisoned arrows of this locality are apt to cause intense local inflammation with foul-smelling pus and some constitutional disturbance. The recovery from both the wound and the empyema suggests a natural strong resistive power to pyogenic infection.

Lorha, Northern Territories, Gold Coast.

\section{A CASE OF TWIN ECTOPIC PREGNANCY.}

By George W. Johnson, M.A., M.B., B.Ch. Oxon. SURGEON TO JOHN COUPLAND HOSPITAL, GAINSBOROUGH.

THE points of interest in the following case are (1) that it was one of twin ectopic pregnancy; and (2) that no vaginal hæmorrhage occurred until after the completion of the operation, although complete rupture into the peritoneal cavity had taken place.

The patient, aged 41 years, married, consulted me for abdominal pain of some four days' duration. The pain was above the pubes on both sides and was colicky in character. The pulse was 76 and the temperature $98.2^{\circ} \mathrm{F}$. No vomiting and no obvious physical signs beyond some slight tenderness and resistance to pressure above the pubes on either side. Menstruation, previously regular, had ceased ten weeks before "as the result of a severe chill" contracted at the time the monthly period was due. The patient had been married 14 years and had never been pregnant. . There were no changes in the breasts and no signs of pregnancy, which was held to be out of the question. There was no vaginal discharge or hæmorrhage. Two days later an indefinite mass was felt in the left iliac fossa on deep pressure, and per vaginam a considerable swelling was felt to the left of and behind the uterus, and there was a boggy feeling in Douglas's pouch. The pulse and temperature remained normal and there was still no external hæmorrhage, but the pain continued colicky and became more severe.

Ectopic pregnancy was diagnosed and laparotomy was performed. The left tube was ruptured and bleeding and the right tube was congested and closed at the fimbriated end by a thick deposit of lymph. Two fotuses of about ten weeks were found in the peritoneal cavity, with a single large placenta and a quantity of blood clot. The operation was completed as usual and convalescence was uneventful.

Gainsborough.

\section{attedital Sotieties.}

\section{MEDICAL SOCIETY OF LONDON.}

\section{Opening Address.-Experiences in Serbia, 1914-15.}

A MeEting of this society was held on Oet. 11th, Dr. W. Pasteur, the President, being in the chair.

The PrEsident, in his opening address, referred to the difficulties connected with the holding of meetings during the war. This was, he said, reflected in the smallness of the last volume of the Proceedings. It must not, however, be judged by its bulk, for it contained matter of great interest and importance connected with the experiences in military surgery acquired in the present war. The difficulty of making meetings successful was accentuated by the fact that onethird of the total number of the members were engaged on active service either abroad or at home. The war was providing plenty of material for investigation, and our command of the sea allowed of the sending home of the wounded and sick men. In spite of the unspeakable horrors of the present war it would make considerable additions to our medical knowledge. There was considerable difficulty, however, in making adequate use of the material available. At the advanced bases it was no easy matter for notes to be taken, especially during periods of rush, and even those which were taken often failed to get through to England. Moreover, patients who were under observation, when they improved, were often drafted away to convalescent homes before their cases had been completely investigated. Under such circumstances it was inevitable that much of the experience gained by individual workers should be fragmentary. He then referred to two groups of cases which had been under his personal observation. The first were cases of pulmonary tuberculosis. The special features of this condition, as he had obierved it in the soldiers invalided from the service, were the prominence of hæmoptysis and the rapid improvement which occurred when they were placed under favourable circumstances. In the great majority there was a previous history of pleurisy or of actual tuberculosis of the lung. Some had undergone sanatorium treatment, even within a period of two years, before they joined the service. Some of the cases followed pneumonia. The physical signs of the condition were very indefinite, moist sounds especially being scanty or absent. The second group, which provided material of the greatest interest, was the "enteric" group, including typhoid, paratyphoid, dysentery, trench diarrhœa, and intestinal protozoal diseases. Most of these came from the Near Last, but some also from France. They were indefinite in type and benign, and recovery was almost invariable. He considered more particularly the modified typhoid class. Pyrexia of varying intensity and duration was often the only sgmptom or only prominent symptom. The onset was sudden. The pulse-rate, as in ordinary typhoid, was relatively low. There was malaise, but the headache was slight. The abdominal symptoms were indefinite, or perhaps altogether wanting. Spots were not uncommon, but were often indefinite and not always easy to distinguish from the many forms of spots which were seen on the skins of these patients. The spleen was not usually enlarged. The characteristic toxic appearance of a typhoid patient was little in evidence. The fever ended by lysis and convalescence was often ushered in by a few days of subnormal temperature. It had to be remembered that the typhoid met with was modified by inoculation. Bacteriological tests were difficult to carry out. A single agglutination test was of no use in such cases, but it was necessary to obtain a curve from repeated tests in the early stages of the disease, using very considerable dilutions. It was open to question whether trench diarrhca represented relapses of modified typhoid fever. Some cases of that disease failed to react to any agglutination test. The suppression of the abdominal symptoms was the chief distinction of the modified disease. It comprised only a small fraction of a large class of enteric diseases, all of which required careful investigation.

Major J. T. J. MorRISOn, R.A M.O. (T.F.), related his experiences in Serbia in 1914-15.

West London Medico-Chirurgical Society.The opening meeting of the thirty-fourth session of this society was held at the society's rooms, West London Hospital, on Oct. 8th. The retiring President, Mr. Aslett Baldwin, inducted the new President, Dr. Leonard Dobson, into the chair, who then presented the Keetley memorial medal to Mr. Aslett Baldwin.-Dr. Dobson's presidential address, on the subject of Progress in Treatment, after emphasising the profound influence of the discoveries of Lister on medicine as well as surgery, called attention to the results of certain modern operations, notably those for displacements of the uterus and kidney, gastro-enterostomy, and appendicostomy. $\mathrm{He}$ found that in malignant disease early operation was still the only sure method of cure, though the action of radium and the $\mathrm{X}$ rays was remarkable in many ways. In medicine proper he complained that there was too strong a tendency to follow the fashion of the time in the practice of medicine, and he instanced the prevalence of pyorrhœea alveolaris and the needless sacrifice of innumerable sound teeth. Dr. Dobson deplored the neglect of most physicians to make a study of dietetics, the need for which he considered very serious. 